\title{
A Estratégia Nacional de Defesa do Brasil e a dos outros BRICs em perspectiva comparada
}

\author{
The National Defense Strategy of Brazil and other BR/CS \\ in a comparative perspective
}

JOÃO FÁBIO BERTONHA*

Rev. Bras. Polít. Int. 56 (2): 112-130 [2013]

\section{Introdução}

Comparar é sempre uma dificuldade quando pensamos na formatação do pensamento histórico ou estratégico. Sempre se abrem dificuldades teóricas sobre o que pode e o que não pode ser comparado, os elementos da comparação, etc. Não obstante, quando escolhidos com cuidado os termos de comparação, especialmente no tocante às balizas geográficas, temporais e analíticas, a comparação pode ser sugestiva para indicar padrōes, diferenças e permitir extrapolaçôes e análises mais densas.

Penso que isso é especialmente verdadeiro a respeito da Estratégia Nacional de Defesa (END) brasileira. Desde a sua publicação, em 2008, ela recebeu críticas e análises por parte da Academia e da mídia brasileira e internacional, mas sempre de forma isolada, como se o Brasil fosse o único país a estar repensando sua estratégia nacional de defesa frente à necessidade de adaptação a um novo momento da História.

Nesse contexto, os componentes do grupo Brasil, Rússia, Índia e China (BRIC) são especialmente viáveis como objetos de comparação, pois, apesar das diferenças gritantes entre os quatro Estados, é opinião geral que eles representam o grande foco das alterações geopolíticas mundiais no século 21. Justifica-se, pois, que eles sejam comparados e que a END brasileira seja avaliada e comparada com os outros três membros do bloco.

Cabe aqui assinalar que a escolha dos elementos de comparação foi feita da maneira mais simples possível, ou seja, os países constituintes do grupo dos BRICs. A única exceção foi a África do Sul, cuja recente adição ao grupo tornou impraticável a sua incorporação no presente texto, cuja pesquisa e elaboração * João Fábio Bertonha é Professor do Departamento de História da Universidade Federal de Maringá (UEM),
Maringá, Brasil (fabiobertonha@hotmail.com). 
já estava em andamento há um certo tempo. Além disso, certas especificidades sul-africanas me levam a concluir que sua comparação com os outros BRICs e, especialmente, com o Brasil, mereceriam um estudo à parte, suplementando o atual.

Com efeito, tanto Brasil como África do Sul estão relativamente isolados, respectivamente, na América do Sul e na extremidade meridional da África e, além disso, se debruçam sobre o mesmo espaço estratégico em termos navais, o Atlântico Sul, ainda que, evidentemente, o sul-africano também se prolongue pelo Índico. Dessa forma, a comparação do caso brasileiro com o sul-africano merece um estudo próprio, a ser feito no futuro.

$\mathrm{O}$ artigo se dividirá, assim, em várias partes. Inicialmente, examinarei os casos indiano, russo, chinês e brasileiro. Sendo impossível examinar todos os meandros e detalhes das ENDs de cada um desses países, focalizarei minha discussão na avaliação que cada Estado faz da sua segurança interna, do seu entorno geográfico imediato, do equilíbrio estratégico internacional no século 21 (especialmente da sua relação com a potência hegemônica, os EUA) e como eles construíram suas ENDs com o objetivo de dar conta desses desafios e dos seus objetivos para esse novo século.

Ressalte-se, a propósito, que, apesar de esse texto se focar nas Estratégias Nacionais de Defesa e de eu considerar que questôes internas são mais adequadamente definidas como "Segurança" do que como "Defesa" (Bertonha 2012), acabarei fazendo um apanhado também dos problemas de segurança interna de cada país, já que as questões de segurança interna acabam por impactar suas estratégias de defesa ao representarem desvios de recursos ou funçóes dentro das Forças Armadas.

Completada a análise dos casos individuais, farei um panorama comparativo entre eles, de modo a perceber as similaridades e as diferenças entre eles. Novamente, o foco será nos temas centrais vistos acima, ou seja, segurança interna, entorno geográfico, equilíbrio global e relação com os EUA e as respectivas ENDs. A conclusão, por fim, será concentrada na END e na estratégia brasileira de inserção global, as quais são, em última instância, os focos primordiais desse trabalho.

As fontes utilizadas são, em essência, os "Livros Brancos" de cada um dos Estados mencionados ou os seus equivalentes. Dado o caráter público e nem sempre transparente desses documentos, procurei utilizar também uma vasta literatura analítica sobre essas estratégias e sobre os processos de modernização militar em curso nos quatro países. As limitações e as dificuldades inerentes em abordar quatro casos simultaneamente são evidentes, mas espera-se que os resultados que virão desse esforço compensem largamente as dificuldades.

\section{O caso indiano}

A Índia identifica, hoje, o seu entorno estratégico como longe de estável e pacifico. Internamente, ela é uma sociedade na qual os problemas sociais e os 
relacionados aos recursos naturais, à energia e aos desastres climáticos são sérios, com necessidade de desvio de recursos políticos e militares para a sua resolução. Os desafios internos diretamente relacionados à segurança, com o uso extensivo das forças armadas em apoio às policiais, como as guerrilhas maoístas e na Caxemira e o terrorismo também são acentuados e não dão sinal de perder intensidade, senão o contrário (Kugelman, 2011). Um país, portanto, que desvia boa parte dos seus recursos estratégicos para dar conta de graves problemas internos.

Pensando apenas no cenário externo, sua relação com o Paquistão continua tensa e, agora, ela se tornou ainda mais complicada pela posse de um importante arsenal nuclear por ambos. E isso não apenas pelos riscos de um inferno nuclear em ambos os países, mas porque a posse de tais armamentos blindou o Paquistão dos riscos de um ataque convencional indiano e permitiu a esse uma escalada nas escaramuças com a Índia, especialmente por meio do apoio aos insurgentes da Caxemira (Dasgupta e Cohe 2011, 166-167). A ascensão chinesa também começa a despertar cada vez mais desconforto dentro da Índia (Pant 2011), como veremos melhor a seguir. Tudo isso parece estar levando a uma preocupação acentuada com o reforço do aparato militar nacional.

A Índia, na verdade, está longe de ser um país desarmado. Hoje, ela tem o terceiro maior Exército do mundo, a quarta Força Aérea e a quinta Marinha, além de uma sólida base tecnológica. Seu orçamento militar passou de US\$ 12 bilhōes em 2000 para US $\$ 30$ bilhōes em 2010 e acredita-se que subirá para cerca de US\$ 60 bilhôes anuais nos anos a seguir. É verdade que, como proporção do PIB, o gasto permanece constante ou mesmo em leve declínio, mas o aumento dos recursos tem permitido uma substancial melhora das várias forças e aquisições maciças de novos armamentos no mercado internacional, as quais devem atingir cerca de US\$ 50 bilhōes (ou mesmo mais) entre 2010 e 2015 (Kugelman 2011, 12; Srivastava 2011, 69). Uma nova potência militar está claramente sendo montada e resta perguntar o que a Índia fará com esse novo poder.

A Índia, na verdade, tem sido um Estado bastante reticente, apesar do seu envolvimento em várias guerras e conflitos, ao uso da força para perseguir seus interesses nacionais. Segundo o trabalho de Dasgupta e Cohen (2011), as elites indianas tenderiam a não identificar a força militar como apropriada como instrumento da política externa. Uma herança dos pais fundadores da Índia (Nehru e Gandhi), os quais, como consequência, teriam insistido no não alinhamento e em baixos gastos militares.

Nesse contexto, as ações militares indianas (a intervenções na Caxemira, e as guerras e choques contra o Paquistão e a China) teriam sido mais reativas e conjunturais e terminado, normalmente, de forma desastrosa para os interesses nacionais indianos. Sem capacidade militar suficiente e com hesitação em utilizálos além de um limite, os indianos não teriam conseguido alavancar seus objetivos e aspirações com o argumento da força. Mesmo o hiato de 24 anos entre os testes 
nucleares de 1974 e 1998 seria uma confirmação dessa tendência do país em enfatizar a moderação acima de tudo.

O governo de Rajiv Gandhi (1984-1990) teria representado uma primeira mudança nessa doutrina, com um programa maciço de aquisição de armamentos modernos (especialmente da URSS) e tentativas de utilizar o poder militar indiano de forma mais assertiva, mas sem muito sucesso, até porque os recursos militares ainda eram escassos e a doutrina da contenção estratégica continuava em vigor.

$\mathrm{Na}$ última década, dada a maior disponibilidade de recursos para financiar a modernização militar, a ascensão de governos mais nacionalistas e o crescimento da ameaça representada pela China e pelo Paquistão, vários autores têm proposto que a contenção estratégica indiana estaria em vias de terminar e que uma nova era se iniciaria. Dasgupta e Cohen (2011, 170-175) não compartilham dessa visão e acreditam que o programa de rearmamento indiano é ocasional e sem uma diretriz estratégica precisa, já que haveria enormes dificuldades de relacionamento e coordenação entre as lideranças civis e militares, pré-requisito para a formatação de uma estratégia coerente de defesa nacional.

Segundo eles, a Índia não estaria realmente projetando e se preparando para uma guerra com a China, nem para um conflito nuclear com o Paquistão ou para projetar poder no Oceano Índico. As preocupaçōes centrais do aparato de defesa e segurança continuariam a ser a insurgência maoísta e na Caxemira e o terrorismo. No entanto, as compras das forças estariam se concentrando em tanques, avióes e navios, enquanto a modernização da polícia e do sistema judicial (chaves para a segurança interna) estaria sendo negligenciada, o que revelaria um descompasso entre a estratégia e as políticas de modernização das forças.

No entanto, talvez os próprios argumentos utilizados por esses autores possam ser utilizados para indicar o contrário, ou seja, que, aos poucos, a doutrina de contenção estratégica está a ser substituída por uma mais proativa. No tocante ao Paquistão, as forças armadas indianas tiveram que se adaptar às regras da dissuasão nuclear, mas estão buscando maneiras, como a doutrina chamada de "Cold Start", para punir o Paquistão pelo seu apoio aos insurgentes na Índia sem arriscar um conflito nuclear. Talvez tal doutrina seja falha, precária e ocasional (Chari 2011), mas isso pode estar indicando uma tendência de uma postura mais ativa, ainda que dentro da nova realidade nuclear.

O mesmo pode ser dito com relação à China. Disgupta e Cohen têm razão ao afirmar que a Índia tem seguido a política da moderação no tocante à China, sem perseguir, por exemplo, um equilíbrio nuclear com Pequim. No entanto, o aumento recente da presença militar indiana (incluindo novas bases aéreas e divisões de montanha) nas fronteiras com a China pode indicar um início de reversão desse quadro. Além disso, as forças armadas, especialmente o Exército, começam a repensar sua doutrina, identificando numa "guerra em dois frontes", contra a China e o Paquistão, o principal desafio para o qual as forças devem se preparar (Ahmed 2010). 
Quanto ao Oceano Índico, está mais do que clara a preocupação indiana com a crescente presença chinesa no "seu" oceano e o seu enorme esforço em readquirir predominância estratégica na região, por meio da ação diplomática, da especial ligação com os EUA e da construção de uma poderosa Marinha oceânica. Com relação a essa, os planos são de dispor, ao final dessa década, de três grupos de batalha centrados em porta-aviōes, além de submarinos nucleares de ataque e lançamento de mísseis balísticos e 150 navios de superfície (Pant 2011; Srivastava 2011). A China ainda terá mais navios e marinheiros, mas, no contexto do Índico, a Marinha indiana estará em boa posição para adquirir hegemonia estratégica e responder ao desafio chinês (Prakash 2011; Hedrick 2009; Kugelman 2011).

Enfim, se a contenção estratégica indiana está realmente sendo abandonada em favor de uma mais assertiva, se esse possível abandono seria um bem ou um mal para os interesses internacionais indianos e se a Índia conseguirá adquirir poder suficiente para equilibrar a força chinesa são pontos em aberto. Não obstante, a avaliação que faço é que o Estado indiano está percebendo o seu entorno estratégico como cada vez menos pacífico e estável e se preparando para dar conta dessa situação, ainda que com muitas improvisações e problemas, por meio do fortalecimento da sua máquina militar.

Nesse contexto, não espanta que os Estados Unidos identifiquem na Índia a sua mais promissora aliada entre os BRICs, considerando que uma cada vez mais poderosa e influente Índia é um interesse nacional dos Estados Unidos. Para Washington, a Índia é uma parceira fundamental na resolução de vários problemas comuns (terrorismo, energia, etc.), assim como para manter o equilíbrio de poder na Ásia, colocando em cheque a cada vez mais poderosa China. Essa visão de uma aproximação mutuamente benéfica parece estar sendo compartilhada também pelos indianos, ainda que, claro, com as declarações públicas de praxe evitando mencionar isso e críticas e dúvidas de parte a parte (Blackwill 2011).

Em resumo, a Índia não parece identificar um cenário mundial excessivamente competitivo e que a obrigaria a criar força dissuasória maior do que a já existente, incluindo a nuclear. No entanto, ela vê, internamente e no seu entorno regional, um emaranhado de problemas que sugere a necessidade de uma estratégia de defesa, ainda que não escrita formalmente, mais voltada ao equilíbrio de poder regional e ao enfrentamento dos problemas do terrorismo e das guerrilhas. Paquistão e China continuam a chave dos problemas estratégicos indianos e sua END gira em torno deles. Isso já era identificado em 2002 (Chambers 2002) e, dez anos depois, essa concentração é ainda mais clara.

\section{O caso russo}

Não é esse certamente o espaço para apresentar a longa história russa dentro do sistema internacional e nem a catástrofe geopolítica sofrida pelo país nos anos 1990, quando não apenas a sua sociedade empobreceu, como o seu Estado viu 
seu poder militar e sua influência internacional cair a níveis mínimos. Também não é o caso de descrever em detalhes a recuperação, ainda que limitada, do status internacional russo e do seu poder militar na década passada, o que já fiz em outros espaços (Bertonha 2009). O foco há de ser o momento presente e as perspectivas russas para o futuro.

A Rússia do século 21 prevê um aumento da sua capacidade militar, especialmente por meio de um maciço programa de modernização e profissionalização das forças. Em 2008, um dos maiores e mais radicais programas de reforma do aparato militar foi desencadeado na Federação Russa, atingindo a estrutura das forças como um todo, da quantidade e qualidade dos oficiais, soldados e unidades à instalação de novos sistemas de comando e controle, aquisição de novos armamentos, etc.

A ideia é fazer um corte no efetivo das tropas, o qual deverá cair para cerca de 1 milhão de homens em 2012, e um ainda mais radical no corpo de oficiais, o qual deverá ser reduzido em dois terços. $\mathrm{O}$ número de unidades e bases será radicalmente reduzido e tanques, avióes, navios e outros equipamentos também serão descartados em massa. O número de navios da Marinha, por exemplo, será reduzido à metade e o número de tanques cairia dos atuais 23 mil para apenas 3 mil, mas de última geração (Savelyev 2011, 165-172).

A estrutura básica de combate seria a brigada, com uma estrutura de comando mais enxuta, e haveria aquisiçôes maciças de armas e equipamentos de última geração, numa lista de aquisiçôes que atingiria várias centenas de bilhões de dólares na próxima década. O objetivo, por 2020, seria dispor de unidades aéreas e terrestres perfeitamente adestradas e equipadas para a guerra moderna, uma Marinha em condições de exercer alguma capacidade de projeção de poder além da Eurásia e uma força nuclear pequena, mas capaz de exercer seu papel de dissuasão. Em resumo, a essência da reforma é privilegiar a qualidade sobre a quantidade, no que seria uma reversão notável da tradição militar russa.

Examinando as várias doutrinas militares produzidas pelo establishment militar russo do ano 2000 até hoje (De Hass, 2011; Kipp, 2011), é possível ter um insight razoavelmente preciso da visão atual de Moscou sobre os desafios estratégicos enfrentados pelo país e das razões da reforma acima mencionada.

Efetivamente, a doutrina militar russa é mais abstrata e tem mais consistência política do que as doutrinas equivalentes dos Estados ocidentais. Assim, ela oferece, nas suas várias encarnações, um panorama razoável a respeito dos desafios e ameaças identificados e as necessidades das várias forças e serviços armados para enfrentá-los.

Quando examinamos os vários documentos (2000, 2003, 2008 e, especialmente, a edição mais recente, de 2010), é possível perceber a alteração no pensamento estratégico russo nessa última década. De uma postura defensiva, a postura russa se tornou mais assertiva, tanto pela recuperação do hard power russo, como, especialmente, pelo enfraquecimento da aproximação com o Ocidente. 
Os russos, hoje, parecem ver o mundo com olhos mais preocupados e dispostos a agir ativamente em defesa dos seus interesses.

A Rússia identifica vários problemas internos a serem enfrentados, como o terrorismo islâmico, o separatismo em várias províncias e, em especial, na Chechênia, e outros. Para isso, mantém um substancial aparato de segurança interna. No campo externo, seus maiores problemas parecem estar na relação com o Ocidente e no antigo território da URSS.

A expansão da Organização do Tratado do Atlântico Norte (OTAN) para a Europa do Leste e o Cáucaso parece ser vista, realmente, como um risco potencial (Giles 2010), a ser enfrentado com todas as forças do Estado. Já a ingerência de outros países nos antigos países membros da URSS é identificada como um perigo para a hegemonia russa na área que Moscou identifica como de sua competência. Isso explica porque a Rússia, apesar de não estar em conflito direto com o Ocidente e, em particular, com os EUA, está claramente em disputa com este nos mais variados campos (Blanck 2009). Moscou, efetivamente, parece olhar, ao menos no momento atual, com mais preocupação para suas fronteiras ocidentais do que para as orientais, mesmo com uma China cada vez mais poderosa ao seu lado.

A doutrina de 2010 não menciona a enorme reforma pela qual as Forças Armadas da Federação Russa estão passando desde 2008. E, pelo contrário, parece contradizê-la, pois defende a capacidade de mobilização de imensas massas de recrutas em defesa da Nação, ao mesmo tempo em que nas reformas enfatiza a necessidade de profissionalizar e modernizar as Forças Armadas (De Haas 2011, 54-55).

Mesmo com essa aparente contradição, contudo, me parece que as reformas indicam perfeitamente como os russos identificam o cenário atual e se propóem a enfrentá-lo. A capacidade militar que eles buscam não é dissuasória (pois a sobrevivência do Estado já está garantida por meio do aparato nuclear e da aberta disposição em utilizá-lo se necessário) e nem tem como prioridade a projeção de poder fora da Eurásia. Alguma capacidade nesse sentido está sendo preparada, especialmente em termos navais, mas a ênfase é realmente a recuperação da hegemonia estratégica no seu entorno. Recuperar o entorno para iniciar o retorno ao cenário global parece ser a perspectiva russa.

\section{O caso chinês}

A China é, com certeza, a mais séria candidata a superpotência no século 21. Já é de domínio comum a sua provável ascensão a primeira economia do mundo em poucos anos, sua crescente influência política e cultural e a sua presença, em todos os níveis, nos mais remotos rincôes do planeta.

De forma coerente com essa ascensão econômica e política, a China está reforçando imensamente a sua capacidade militar. Há vários anos, seu orçamento militar oficial cresce a níveis elevados - US $\$ 80$ bilhões em 2010 - e calcula-se que 
o seu orçamento real pode chegar a três vezes esse número. Mesmo mantendo-se em níveis moderados em relação ao PIB, o crescimento é contínuo e tem permitido uma crescente profissionalização e modernização das Forças Armadas (Davies e Rothe 2011).

O resultado é mais do que evidente. Uma nova força está emergindo, menor (mas ainda imensa), com equipamento modernos oriundos da Rússia e, cada vez mais, produzidos localmente (como os novos caças J-20), nova doutrina e novas prioridades (Blasko 2005). As forças armadas chinesas caminham rapidamente para um padrão de ênfase na tecnologia, na qualidade sobre a quantidade e no abandono do padrão quase miliciano do passado (Wortzel 1999; Stoakes 1999; Kamphausen e Stobell 2007).

A China ainda não é uma superpotência militar e, mesmo localmente, suas capacidades são mais de interdição do que de projeção de poder. Boa parte das elites militares estão mais preocupadas com a ordem interna e com as inúmeras empresas geridas pelos militares do que com um projeto claro de construção de hegemonia militar mundial.

Além disso, é evidente que não se pode ter certeza de que sua ascensão econômica e militar continuará e o simples acúmulo de elementos do poder militar não significa automaticamente poder e disposição para utilizá-lo (Wortzel 1998). Não obstante, os progressos chineses são evidentes e tudo indica que continuarão, dando à nova superpotência econômica um sólido braço militar, ainda que seja impossível precisar com certeza até onde esse braço pretende chegar.

No seu mais atualizado documento relacionado ao tema da estratégia nacional de defesa (China 2011; Davies e Rothe 2011), os objetivos e a visão chinesa do atual contexto mundial acabam por surgir nas entrelinhas, depois de um sem número de frases e parágrafos ressaltando o caráter totalmente pacífico, cooperativo e defensivo da sua estratégia, o que é, de resto, comum aos Livros Brancos de quase todos os países.

Nesse sentido, ficam evidentes as preocupações chinesas com o terrorismo e com movimentos independentistas no seu território, especialmente no Turquestão e no Tibete. Também é mencionada, sem novidades, a preocupação da China com a reconstrução do seu espaço perdido na era colonial e, em especial, com a questão de Taiwan.

Para o curto e médio prazo, as elites chinesas parecem preocupadas com os riscos de que potências extra-asiáticas (leia-se os Estados Unidos) possam tentar impedir a ascensão chinesa e restringir o espaço chinês na sua própria vizinhança. A China não está em rota de colisão com os EUA no presente momento, mas seu objetivo de médio prazo parece ser o de criar uma ordem asiática sem a presença americana e isso só pode gerar uma situação de cautela e desconfiança (ainda que mesclada por interesses e dependência mútuos) entre Washington e Pequim (Chase 2011; Pumphrey 2002). Não espantosamente, os Estados Unidos também começam a se preocupar, ainda que de forma moderada, com os avanços chineses 
tanto na Ásia como em outras áreas do mundo, como na América Latina (Bertonha 2010; Ellis 2009, 2010).

Não espanta, assim, que ao mesmo tempo em que a liderança chinesa identifica vários riscos internos à sua segurança (suprimento energético, meio ambiente, contradições sociais) e identifique na Índia e no Japão (mas não, ao menos no presente momento, na Rússia) potenciais rivais, seu foco principal de preocupaçôes é a presença do poder americano na Ásia (Craig 2007).

Dessa forma, garantir seu "espaço exclusivo" e o aprovisionamento de energia e matérias-primas necessárias para a continuidade do seu crescimento econômico (incluindo crescente presença nas vitais rotas marítimas) são os objetivos imediatos da China, enquanto se preparam os futuros estágios para metas maiores, as quais, contudo, ninguém sabe definir ao certo, o que leva à produção acelerada e maciça de análises e conjecturas por parte dos analistas ocidentais (Kamphausen e Stobell 2007).

O que é cristalino, com efeito, é que a China identifica, na sua ascensão econômica, geopolítica e militar, a recuperação do seu "século de humilhação" nas mãos das potências europeias e do Japão e a recuperação de seu "lugar devido" como centro do sistema internacional. Esse objetivo de longo prazo parece estar presente na cultura estratégica chinesa, ainda que não pareça estar corporificado em metas e objetivos claros e precisos.

A modernização militar chinesa parece estar caminhando nessa direção, focando mais nos problemas de curto ou médio prazo do que nos de longo prazo. Depois de garantir a não interferência externa no seu território e de adquirir os instrumentos para, no mínimo, tornar custosa uma ação americana em defesa de Taiwan, a China está caminhando a passos largos na direção de uma capacidade militar suficiente para uma hegemonia no seu entorno.

Não espantosamente, apesar de todas as forças armadas chinesas estarem em processo acelerado de modernização, as prioridades são as forças nucleares, a Marinha e a Força Aérea. O Exército, que é ainda a força principal, está recebendo, proporcionalmente, a menor parte dos recursos, o que indica a reorientação da estratégia militar chinesa na direção do oceano e dos arredores.

A China, assim, continua a aumentar sua já imensa força de submarinos (fundamental para tentar impedir à Marinha dos EUA o acesso aos estreitos de Taiwan) e inicia os primeiros passos para uma verdadeira Marinha oceânica, incluindo vários grupos de batalha de porta-aviōes. Esse último objetivo ainda está distante e a Marinha chinesa ainda tem imensas dificuldades em manter operações navais fora do Mar da China (Yung e Rustici 2010), mas a caminhada nessa direção parece real.

Por agora, a sua política externa tem sido marcadamente moderada e pacífica, mas recentes acontecimentos têm levado alguns a acreditar que sua estratégia nacional possa estar se tornando mais assertiva e mesmo agressiva (Godement 2011). Além disso, a preocupação maior dos que têm que lidar com a China é 
com o futuro, quando ela, imensamente poderosa, talvez não precise mais manter o low profile de hoje em dia.

O próprio crescimento do poder chinês, contudo, pode, num clássico "paradoxo da segurança", acabar se tornando um problema para a sua hegemonia regional, necessária para pensar num futuro papel predominante em nível mundial. O temor da China está induzindo vários dos seus vizinhos - Índia, Japão, Austrália, os países da Associação de Nações do Sudeste Asiático (Asean) e outros - a se fortalecerem militarmente e a se aproximarem uns dos outros e também dos Estados Unidos (Pumphrey 2002; Bagchi 2011).

Isoladamente, esses Estados não teriam como fazer uma política de "equilíbrio de poderes" com a China e nem a Índia é forte o bastante para isso - tanto que se projeta que, ainda em 2025, a China estará gastando entre quatro e sete vezes mais em defesa do que a Índia (Wolf 2011, 110). Mas unidos e com apoio dos EUA, eles podem colocar em cheque o desejo hegemônico chinês para a região.

Uma busca de hegemonia local, com ambiçōes maiores e incertas para o futuro, mas procurando atingi-las, inicialmente, com o mínimo de confrontação possível com os vizinhos e com os Estados Unidos. A estratégia de defesa chinesa é claramente defensiva e pacífica, restando apenas a dúvida se ela continuará - ou poderá continuar - a ser assim no futuro.

\section{O caso brasileiro}

O Brasil sempre teve algumas especificidades no tocante aos seus vizinhos hispano-americanos. Em primeiro lugar, a língua portuguesa e a herança lusitana sempre fizeram os brasileiros se sentirem uma ilha, ainda que continental, num oceano de povos e Estados falantes do espanhol.

Em segundo, o simples fato de a América portuguesa ter permanecido unida enquanto a hispânica se desagregou deu, ao nascente Estado brasileiro, um território e uma população imensos e sonhos de grandeza, de potência que um dia ascenderia ao primeiro plano em termos globais. Na América Latina, creio que o único Estado que sonhou com uma posição internacional igual foi a Argentina entre fins do século 19 e a metade do 20 . No caso brasileiro, contudo, essa ambição ou desejo fez parte da cultura estratégica brasileira desde a época imperial, passando por todo o século 20, e está presente ainda hoje.

Por outro lado, apesar dessa ambição ou sonho, a imensa pobreza da sociedade brasileira e a fraqueza do Estado o levaram a imensa moderação e até passividade no sistema internacional. Com a exceção de uma política de equilíbrio de poderes no Cone Sul - especialmente no tocante à Argentina, no passado -, o Brasil sempre pautou a sua inserção internacional numa política de associação a Estados maiores (como os Estados Unidos em boa parte do século 20) e numa defesa do multilateralismo, das leis e da negociação como forma de resolver conflitos. Uma política coerente com a de um Estado de poder médio, que marcou e marca a 
relação do Brasil com o mundo e que, apesar de mudanças recentes, ainda é parte integrante da cultura estratégica brasileira.

Nos últimos anos, à medida que a sua situação econômica tem melhorado consideravelmente e que o país avança para uma melhor posição relativa no sistema internacional, a estratégia nacional brasileira sofreu alteraçôes de monta, com uma inédita concentração de esforços na direção da integração da América do Sul e um protagonismo inédito no cenário mundial.

Não obstante, os eixos da estratégia brasileira continuam, em síntese, os mesmos: garantir uma posição relativa melhor ao Brasil no mundo do século 21 por meio da unificação da América do Sul ao seu redor, da crescente exclusão dos Estados Unidos desse espaço e do reforço do sistema legal e multilateral mundial, incluindo a criação de coalizões com outros Estados que também buscam a superação do mundo unipolar. Do mesmo modo, o País continua tentando atingir esses objetivos procurando evitar a confrontação ou o uso da força, buscando o meio da negociação, do uso do soft power e dos investimentos.

Esses instrumentos, claro, podem não conduzir aos resultados esperados. Como bem indicado no seminal estudo de Hal Brands (2010), esses objetivos e essa estratégia têm atingido resultados positivos, mas vários dilemas e problemas podem atrapalhar os planos de Brasília, como os graves problemas ainda existentes na economia brasileira (como a infraestrutura e a baixa qualidade da educação), as resistências à liderança brasileira na América do Sul, a pouca densidade de várias das alianças formadas recentemente (como a do grupo dos BRICS, o G-4 ou o G-20) e os riscos de tensão com os Estados Unidos.

De qualquer modo, é essa a primeira especificidade brasileira frente aos outros BRICs, ou seja, a menor confiança na força militar ou mesmo no peso econômico para sustentar seus planos. O Brasil não tem, e não terá, por muitos anos ainda, a força econômica ou militar necessária para sustentar algum tipo de competição mais densa com os Estados Unidos, a China ou a Rússia e não acredita que a aquisição de tais elementos de poder seja algo necessário.

Uma segunda especificidade, e grande vantagem estratégica brasileira em relação aos outros BRICs, é a estabilidade interna. Apesar das diferenças regionais, da imensa desigualdade social e de uma histórica subordinação dos afrodescendentes aos de origem europeia, o país não tem conflitos religiosos ou étnicos de monta e a questão indígena, que inflama - com ou sem razão - boa parte da América Latina, é menor.

O sentimento nacional, apesar das imensas diferenças, é absoluto, sem separatismos ou problemas similares. As instituiçôes também são razoavelmente sólidas e a estabilidade econômica e política é um fato. Guerrilha e terrorismo também não existem, a não ser potencialmente, e mesmo o problema da criminalidade é contornável e visto como um problema essencialmente policial e não militar, salvo em momentos excepcionais. 
Uma terceira vantagem brasileira é que o entorno brasileiro também é bastante tranquilo. Há sérios problemas de estabilidade interna no arco andino e na Venezuela e as fronteiras brasileiras são permeáveis (ainda que esforços na direção do seu controle aéreo e terrestre tenham sido feitos nos últimos anos) ao tráfico de drogas e armas e à criminalidade em geral. Mas não há nenhuma superpotência na vizinhança imediata, nenhum vizinho agressivo que ameace a soberania nacional ou mesmo que pudesse servir como contrapeso à hegemonia regional do País. Os candidatos do passado (como a Argentina) ou os potenciais do presente (como a Venezuela) já aceitaram, ainda que não sem mágoas, a nova situação.

Os enormes esforços brasileiros para constituir, pela negociação e por meio de instituições supranacionais - como a União de Nações Sul-Americanas (UNASUL), o Conselho de Segurança sul-americano e a nova Comunidade dos Estados LatinoAmericanos e Caribenhos (CELAC) -, um espaço próprio de influência regional também estabilizaram a área e o protagonismo brasileiro na área militar só reforçou isso (Bertonha 2010a, 2011). Uma vizinhança "tranquila", com os limites que a palavra traz. Como indicado por Fishmann e Manwaring (2010, 2), o Brasil está bem situado no tempo e no espaço.

A END brasileira reflete essa realidade, reconhecendo a situação única do Brasil em termos de estabilidade interna e no entorno imediato e também a nova fase em que o Estado brasileiro está entrando em termos de suas relaçōes internacionais, mas sem abandonar as suas tradições diplomáticas e estratégicas. Nesse sentido, a END prioriza o desenvolvimento tecnológico (na área dos equipamentos militares, na pesquisa espacial e na energia nuclear para fins pacíficos), a segurança das fronteiras e, acima de tudo, a dissuasão contra inimigos de fora da América do Sul.

Refletindo essa nova realidade, o Estado brasileiro tem ampliado os seus gastos militares, os quais mais que dobraram entre 2003 e 2010, ainda que estejam longe do patamar dos outros BRICs, para não falar dos Estados Unidos. Novos equipamentos foram adquiridos e, à parte interesses corporativos ou circunstanciais que levaram a algumas aquisições aleatórias, o foco das compras e dos projetos tem sido mais para a proteção das fronteiras e para dissuasão do que para a projeção de poder.

Não espanta, assim, que o único porta-aviōes nacional esteja semiabandonado enquanto a Marinha prioriza os submarinos, especialmente os nucleares, para a defesa do mar territorial. Ou que a Força Aérea esteja se concentrando na vigilância da Amazônia e em ampliar a sua capacidade de transporte, enquanto o projeto de aquisição dos caças de última geração continua sem definição. $\mathrm{Ou}$, ainda, que a END continue insistindo na mobilização nacional ou na guerra assimétrica para a proteção da soberania contra invasores, ao mesmo tempo em que reconhece que o desenvolvimento tecnológico é a chave do futuro.

Essas aquisições e a nova END (com todos os seus limites e contradições) (Bertonha 2011) indicam um Brasil mais preocupado com as suas fronteiras, com 
a estabilidade dos seus vizinhos e com os riscos à sua soberania por Estados mais poderosos. O País caminha, assim, na direção de maior autonomia e influência estratégica, incluindo a hegemonia militar regional, mas sem ênfase exagerada nesse ponto, preferindo tentar garanti-la via instituições supranacionais e pelo seu próprio peso econômico.

Tenho dúvidas (Bertonha 2010b) quanto a se a confiança brasileira na negociação não acaba por levar a uma quase passividade e acredito que, no futuro, alguma capacidade maior de projeção de poder será necessária. Também penso que a posição da diplomacia brasileira de, por princípio, negar o uso da força como instrumento de política externa tende a enfraquecer o soft power brasileiro e não o contrário. É uma clara contradição, a propósito, o enorme esforço para conseguir um assento no Conselho de Segurança da ONU com a incapacidade, atual e no futuro próximo, de projetar poder, mesmo dentro da estrutura da ONU. Não obstante, talvez seja realmente, no atual caminho do desenvolvimento brasileiro, o melhor caminho a seguir.

No tocante aos EUA, Luigi Einaudi (2011) produziu um interessante texto a respeito das relações brasileiro-americanas, indicando como tais relações sempre oscilaram entre momentos de extrema aproximação com outros de distanciamento, de admiração e inveja a mágoa e ressentimento. Para ele, no momento atual, quando Brasília tenta criar uma área de hegemonia própria na América do Sul e amplia a sua atuação internacional, é provável que os dois países colidam cada vez mais nos foros internacionais e pelo mundo.

Não obstante, não há sinais de confronto aberto ou de diferenças irreconciliáveis. A política brasileira é de buscar autonomia frente à Washington, mas não necessariamente o confronto e muito menos no campo militar. Além disso, o autor chama a atenção para um ponto fundamental, ou seja, que Brasil e Estados Unidos pertencem à mesma civilização, a ocidental, e que os dois países são mais parecidos do que diferentes. Essa aproximação, mais a falta de tensão estratégica real, indicam mais a necessidade de diálogo e engajamento de lado a lado do que um conflito em potencial.

\section{Os BRICs e sua diversidade}

Falar dos BRICs e do seu papel na geopolítica do século 21 se tornou quase um lugar comum, com Brasil, Rússia, Índia e China se tornando as vedetes das relações internacionais nesse início de século. Esses quatro países formam o bloco emergente nas decisões mundiais e isso já estaria se manifestando em organizaçôes multilaterais várias, em reunióes como as de Brasília em 2010 e em outras iniciativas.

Com certeza, a ascensão desse bloco (e de outros países médios, como a Indonésia, o México ou o Irã) representa uma transformação radical na economia e na distribuição de poder mundial nos anos a seguir. Iniciativas conjuntas de 
Moscou, Brasília, Nova Déli e Pequim também têm tido repercussão, especialmente em fóruns como o G-20 e outros.

É questionável, contudo, se haveria alguma chance de esse bloco criar uma política comum, especialmente em termos estratégicos, já que os interesses dos quatro estão mais distantes do que próximos, salvo em questôes específicas, como a busca de maior espaço frente ao poder tradicional dos EUA e da Europa. A sigla BRIC, na verdade, indica uma homogeneidade que não existe.

Acredito, inclusive, que, mais do que a ascensão dos BRICs ou do "resto" frente ao Ocidente, seria mais correto falar simplesmente em ascensão asiática. Índia, China e o seu entorno são responsáveis pela maior parte do dinamismo econômico dos BRICs e é a ascensão econômica, política e militar desses países que está revolucionando o sistema internacional. Brasil e Rússia têm potencial para influir no novo sistema, mas não são a base da sua mudança.

Além disso, tanto Brasil como Rússia são partes do mundo ocidental (ainda que com especificidades) ou, no mínimo, os mais próximos ao Ocidente em todos os aspectos, culturais, populacionais, na formação do Estado, etc. Ao escrevermos sobre a "decadência do Ocidente", talvez fosse interessante especificar que essa decadência, se real, se refere ao núcleo europeu e norte-americano e não necessariamente a todo o universo ocidental.

O uso do termo BRIC também encobre um fato evidente, ou seja, que os elementos de poder disponíveis para cada uma das quatro nações são muito distintos e que, justamente por isso, a sua capacidade em influenciar as grandes decisóes mundiais não é exatamente a mesma.

A Rússia, por exemplo, é uma potência militar de primeira grandeza, com tradição diplomática e capacidade de projeção de poder, ao menos nas vizinhanças. No entanto, sua recuperação econômica ainda é incerta, já que é fortemente baseada no petróleo, sua população está em queda e seu apelo cultural é limitado (Bertonha 2009, 2009a). A Índia também conta com um aparato militar razoável e uma economia em crescimento, mas sua vizinhança é relativamente hostil e sua estabilidade interna questionável.

A China tem uma economia em forte crescimento, um aparato militar sendo modernizado e uma capacidade de atuação internacional em clara ascensão. A razoável capacidade de exportação da cultura chinesa e seu perfil moderado nas relaçôes internacionais também são elementos em seu favor. Mas não se sabe se o Partido Comunista chinês será capaz de dar conta da monumental tarefa de modernizar aquela sociedade sem que o seu tecido social se rompa e a escassez de matérias-primas e energia pode se revelar um problema no futuro.

O Brasil está em outro patamar. Sua economia é mais moderna e madura do que a chinesa, a indiana e mesmo a russa, e até por isso não consegue crescer no mesmo ritmo das asiáticas. O País também tem dificuldades, especialmente no campo da educação, para se converter em uma sociedade e economia do 
conhecimento. Mas o crescimento nos últimos anos tem sido consistente e, se prosseguir, colocará o País, finalmente, entre as primeiras economias do mundo. Energia, alimentos e matérias-primas também são abundantes e são pontos a favor do crescimento sustentado nacional. A imagem do Brasil no mundo, em geral, é bastante positiva e, numa vizinhança sem grandes rivais, a ascendência brasileira pode se manifestar sem grandes problemas.

Pensando em termos comparativos, nota-se, em termos estratégicos, a partir do exposto nos itens anteriores, que os quatro países se aproximam na busca de um mundo multipolar, no qual seus interesses possam ser mais bem representados. Também fica evidente que os quatro Estados estão buscando reforçar seu poder por meio da aquisição de algum tipo de hegemonia no seu entorno imediato, na melhor preparação militar e no maior protagonismo diplomático, enquanto acumulam os recursos geopolíticos para, talvez, ambiçōes ainda maiores no futuro.

Também chama a atenção o fato de que nenhum dos quatro Estados assuma a ideia de que o foco das suas forças armadas sejam as "novas ameaças", as "ameaças assimétricas" ou o combate à criminalidade. Todos se preocupam com a sua estabilidade e segurança internas, mas ninguém acredita que devam converter completamente suas forças armadas para um perfil mais policial do que militar.

As diferenças entre os vários BRICs, contudo, talvez sejam mais importantes do que as semelhanças. Todos têm ambições de um protagonismo global, mas a única que pode se tornar uma nova superpotência, ao menos em longo prazo, é a China. China e Rússia já estão no centro do poder mundial, ou seja, no Conselho de Segurança da ONU, enquanto Índia e Brasil podem apenas ambicionar a isso. Por fim, todos os BRICs contam com arsenais nucleares, sendo o Brasil a única exceção, o que deixa este último menos seguro do que os primeiros.

China, Rússia e Índia também têm que lidar com situações internas potencialmente explosivas, enquanto a brasileira é bem mais tranquila. Do mesmo modo, o entorno brasileiro é mais estável do que o dos outros e o próprio isolamento da América do Sul é positivo para o Brasil, enquanto Rússia, Índia e China (mais a União Europeia e o Japão) colidem na Eurásia, com os Estados Unidos ao fundo.

Isso ajuda a compreender as especificidades da END brasileira e a sua modernização militar. Confiando na negociação e na simples hegemonia estratégica (fácil de conseguir, dado o diferencial de poder com seus vizinhos) para manter a estabilidade ao seu redor e sem grandes problemas internos a enfrentar, a END brasileira foca na dissuasão contra inimigos fora da América do Sul e em instrumentos dissuasórios alternativos como o submarino nuclear; para se defender, sem dar ênfase ao uso da força como instrumento válido da sua política externa, ao contrário dos outros.

Não espanta, assim, que, enquanto a relação dos EUA com a Rússia pareça caminhar para a desconfiança, a com a Índia para a aliança e a com a China para o antagonismo, a de Washington com Brasília caminha cada vez mais para a acomodação. Russos e chineses parecem ter por objetivo excluir os EUA das suas 
áreas de influência, enquanto a Índia procura manter os EUA engajados na sua região. $\mathrm{O}$ Brasil quer autonomia e predomínio na sua região, mas sem excluir a convivência com os EUA. Diferenças que indicam não apenas posturas diferentes frente à potência hegemônica, mas suas próprias visões estratégicas e frente ao futuro.

\section{Conclusões}

O mundo do século 21 provavelmente não será de guerras entre os grandes Estados, já que a simples existência das armas nucleares, a crescente cooperação internacional e as forças da globalização dificultam isso. Mas não será um mundo kantiano, no qual a negociação e as leis superarão completamente o conflito e o uso da força - real ou simbólico - nas relações entre os Estados.

Nesse contexto, os quatro Estados que formam os BRICs identificam suas forças e fraquezas e procuram se adaptar à nova realidade. O Brasil, com as vantagens que a geografia lhe dá e seguindo as suas tradiçóes, avalia o mundo do futuro como mais pacífico e menos conflitivo. Sendo assim, o Estado brasileiro não privilegia o uso da força como forma de projetar seu poder, o que se reflete numa END mais defensiva e numa postura internacional menos assertiva. China, Índia e Rússia, em diferentes gradaçôes, avaliam o cenário internacional de uma forma mais realista e menos idealista e adaptaram suas END a contento.

Só o futuro dirá se a estratégia brasileira é idealista em excesso ou se a dos outros atores peca por um realismo excessivo. Para o momento atual, minha interpretação é que a END brasileira é, apesar de seus defeitos, essencialmente correta e bem adaptada à realidade política e estratégica da América do Sul. No futuro, talvez a médio prazo, contudo, creio que ela terá que ser modificada para dar conta do próprio amadurecimento estratégico nacional.

Nesse sentido, creio que o esforço brasileiro em prezar a negociação e o diálogo é, em essência, um ponto positivo na tradição diplomática brasileira e que tem trazido grandes ganhos ao País. Ainda assim, ela acaba por fazer, do Brasil, uma espécie de "Estado adolescente", que busca o reconhecimento dos "adultos", mas que não sabe exatamente o que deseja e que foge das responsabilidades e dos custos inerentes ao crescimento.

Fica a dúvida, nesse ponto, se o Brasil poderá eternamente se omitir nas grandes questôes e/ou sempre ficar numa posição equidistante em qualquer controvérsia internacional. Também é questionável se, no futuro, o Estado brasileiro não terá que adquirir vetores de poder militar maiores, mais focados na projeção de poder, de forma a dispor dos músculos para bancar sua política externa.

O Brasil também terá que aprender que posições de liderança implicam decisões difíceis, muitas vezes antipáticas, e que o uso da força, real ou potencial, é um instrumento ao qual não poderá renunciar, sob o risco de que sua ascensão ao primeiro escalão do poder mundial seja interrompida. China, Índia e Rússia 
já sabem disso, como souberam todos os grandes Estados na História e o Brasil, provavelmente, também terá que aprender essa lição.

Idealmente, contudo, talvez o Brasil também possa contribuir para um futuro mais pacífico ao ensinar aos outros justamente o contrário, ou seja, que a força militar deve ser apenas um último recurso e um Estado pode influir mais no sistema internacional sem obrigatoriamente recorrer à força, a não ser como último recurso.

\section{Referências bibliográficas}

Ahmed, Ali. Ongoing Revision of Indian Army Doctrine. IDSA Comment, Nova Dheli, 2010. Bagchi, Indrani. "Will China rule the world? A view from New Delhi". India Forum. Paper series. Washington: The German Marshall Fund of the United States, 2011.

Bertonha, João Fábio. Rússia: ascensão e queda de um Império. Uma história geopolitica e militar da Rússia, dos czares ao século XXI. Curitiba: Juruá, 2009.

Bertonha, João Fábio. "O fim da hegemonia americana na América do Sul? Rússia, China e Uniāo Europeia como actores regionais?”, Negócios Estrangeiros (Portugal) 18, p. 121-141, 2010.

Bertonha, João Fábio. "Adquisiciones de armamentos y reequilibrios geopolíticos: América del Sur en la primera década del siglo XXI" Relaciones Internacionales, 39, 39: 109-127, 2010a.

Bertonha, João Fábio. "Brazil: an emerging military power? The problem of the use of force throughout the Brazilian international relations into the 21st century". Revista Brasileira de Politica Internacional, 53, 2: 107-124, 2010b.

Bertonha, João Fábio. Geopolitica, defesa e desenvolvimento. A primeira década do século XXI na América Latina e no mundo. Maringá: Eduem, 2011.

Bertonha, João Fábio. "Seguridad o defensa? Dilemas de las Fuerzas Armadas latinoamericanas en los comienzos del siglo XXI”. Relaciones Internacionales, La Plata (Argentina), 21:19-7, 2012. Blackwill, Robert; Chandra, Naresh e Clary, Christopher. The United States and India. A Shared Strategic Future. Washington: Council on Foreign Relations, 2011.

Blanck, Stephen. Prospects for US-Russian Security Cooperation. Carlisle (PA): Strategic Studies Institute, US Army War College, 2009

Blasko, Dennis. "Chinese Army modernization: an overview". Military Review. 68: 68-73, 2005.

Brands, Hal. Dilemmas of Brazilian Great Strategy. Carlisle (PA), Strategic Studies Institute, US Army War College, 2010.

Chambers, Michael. South Asia in 2020. Future Strrategic balances and alliances. Carlisle (PA): Strategic Studies Institute, US Army War College, 2002.

Chari, PR. Defining India's Security. Looking beyond limited war and Cold War strategies. IPCS Issue Brief 169, 2011.

Chase, Michael. "Fear and loathing in Beijing? Chinese suspicion of US intentions". China Brief. 11, 18: 2-6, 2011.

China's National Defense in 2010. Information Office of the State Council of the People's Republic of China, 2011. 
Craig, Susan. Chinese Perceptions of traditional and nontraditional security threats. Carlisle (PA), Strategic Studies Institute, US Army War College, 2007.

Dasgupta, Sunil e Cohen, Stephen. "Is India ending its strategic restraint doctrine?" The Washington Quarterly 34: 2, 163-177, 2011.

Davies, Andrew e Rothe, Andrew. "Theory and practice. A comparative look at China's new defense White Paper”. Policy Analysis 82. Australian Strategy Policy Insitute, 2011.

De Haas, Marcel. "Russia’s Military Doctrine Development” In Blank, Stephen. Russian Military Politics and Russia's 2010 Defense Doctrine. Carlisle (PA): Strategic Studies Institute, US Army War College, 2011, p. 1-59.

Einaudi, Luigi. "Brasil e Estados Unidos: a necessidade de um engajamento estratégico". Strategic Forum. 266: 1-15, 2011.

Ellis, Evan. China in Latin America. The Whats \& Wherefores. Boulder (CO): Lynne Rienner, 2009.

Ellis, Evan. "What China Will Fight For in Latin America in the Coming Generation". Security and Defense Studies Review, 11, p. 111-120, 2010.

Estratégia Nacional de Defesa, Brasília: Ministério da Defesa, 2008.

Fishmann, Andrew e Manwaring, Max. Brazil's Security Strategy and Defense Doctrine. Carlisle (PA), Strategic Studies Institute, US Army War College, 2010.

Giles, Keit. The Military Doctrine of the Russian Federation. Nato Research Review. Roma: Nato Defense College, 2010.

Global Brasil and US-Brasil relations. New York: Council of Foreign Relations, 2011.

Godement, François “Geopolitics in Chinese terms”. China Analysis. London: European Council for Foreign Relations, 2011.

Pumphrey, Carolyn. The rise of China in Asia: Security Implications. Carlisle (PA), Strategic Studies Institute, US Army War College, 2010.

Hedrick, Brian. India's Strategic Defense Transformation: Expanding Global Relationships. Carlisle (PA): Strategic Studies Institute, US Army War College, 2009.

Kamphausen, Ray e Scobell, Andrew. Right sizing the People's Liberation Army: exploring the contours of China's Military. Carlisle (PA): Strategic Studies Institute, US Army War College, 2007.

Kipp, Jacob. "Russian Military Doctrine: Past, present and future” In Blank, Stephen. Russian Military Politics and Russia's 2010 Defense Doctrine. Carlisle (PA): Strategic Studies Institute, US Army War College, 2011, p. 63-151.

Kugelman, Michael. "Looking in, looking out: Surveying India’s Internal and External Security Challenges" In: Kugelman, Michael. India's Contemporary Security Challenges. Washington: Woodrow Wilson International Center for Scholars, 2011, p. 5-28.

Pant, Harsh. China and India: a rivalry takes shape. Philadelphia: Foreign Policy Research Institute, 2011.

Prakash, Aruh. "The rationale and implications of India's growing maritime power" In: Kugelman, Michael. India's Contemporary Security Challenges. Washington: Woodrow Wilson International Center for Scholars, 2011, 77-88. 
Savelyev, Alexander. "Russian Defense Doctrine" In Blank, Stephen. Russian Military Politics and Russia's 2010 Defense Doctrine. Carlisle (PA): Strategic Studies Institute, US Army War College, 2011, p. 153-179.

Srivastava, Siddharth. "India's Strategic and Political Environment” In: Kugelman, Michael. India's Contemporary Security Challenges. Washington: Woodrow Wilson International Center for Scholars, 2011, p. 69-76.

Stoakes, Mark. China's Strategic Modernization: implications for the United States. Carlisle (PA): Strategic Studies Institute, US Army War College, 2011

Wolf, Charles et allii. China and India, 2025. A Comparative Assessment. Santa Monica (CA): Rand Corporation, 2011.

Wortzel, Larry. China's Military potential. Carlisle (PA): Strategic Studies Institute, US Army War College, 1998.

Wortzel, Larry. The Chinese Armed Forces in the 21 $1^{\text {st }}$ Century. Carlisle (PA): Strategic Studies Institute, US Army War College, 1999.

Yung, Christopher e Rustici, Ross. China's out of Area Naval operations: case studies, trajectories, obstacles and potential solutions. Washington: Institute for National Strategic Studies, 2010.

Recebido em 17 de julho de 2013 Aprovado em 20 de agosto de 2013

\section{Resumo}

O objetivo do presente artigo é examinar as Estratégias Nacionais de Defesa dos quatro países que formam o grupo dos BRICs (Brasil, Rússia, Índia, e China) com vistas a verificar como os quatro países avaliam o cenário estratégico do século 21, especialmente no tocante ao equilíbrio de forças entre as grandes potências, aos seus entornos geográficos imediatos e à relação com os EUA. As semelhanças e diferenças de avaliação e o como isso se reflete nas respectivas políticas de defesa serão abordadas. Dentre os quatro casos, o brasileiro será especialmente enfocado.

Palavras-chave: Brasil; China; estratégias nacionais; Estratégias Nacionais de Defesa; Índia; Rússia.

\section{Abstract}

The main purpose of this paper is to examine the National Defense Strategies of the BRIC countries (Brazil, Russia, India, and China) in order to verify how the four countries evaluate the strategic landscape of this century, especially regarding the balance of power between the Great Powers, their immediate geographical surroundings and their relationship with the US. This work addresses specifically the similarities and differences among them and how these differences reflect in their respective defense policies. Among the four cases, the Brazilian one will be in especial focus.

Keywords: Brazil; China; national strategies; National Defense Strategies; India; Russia. 